\title{
INTRODUCTION OF CENTRAL VENOUS PRESSURE CATHETERS THROUGH ARM VEINS WITH A HIGH SUCCESS RATE*
}

\author{
B. Berly Bridges, Edward Carden, and Frank A. Takacs
}

IN THIS DAY and age, central venous pressure monitoring is commonplace; however, the technique by which central venous pressure catheters are inserted and their site of insertion varies from physician to physician. The traditional approach is to pass the catheter into a monitoring position through the basilic or cephalic vein using the antecubital fossa as the puncture site..$^{1-3}$ Studies have shown that approximately 70-75 per cent of catheter's placed this way will be in a satisfactory position (i.e., within the innominate vein, superior vena cava, or right atrium). ${ }^{2-7}$ Recently, catheters placed through the internal jugular, external jugular, and subclavian veins have become more popular. Insertion of catheters by these techniques is either more complicated (external jugular) or more hazardous to the patient (subclavian, internal jugular). Many reports have cited the associated complications and damage to structures close to these veins in the neck or upper chest. ${ }^{8-14}$

The purpose of this study was to re-evaluate the technique of catheter insertion through the arm veins and to try to perfect a technique which will improve the success rate while maintaining the relatively low complication rate.

\section{Methods and Materials}

The study was divided into four parts. In the first part we inserted various types and gauges of central venous pressure catheters (†Bardic 16 and 18.5 gauge, $\ddagger$ Sorensen 15 gauge, and $\S J$ Jico

B. Berly Bridges, M.D. (Deceased); Edward Carden, F.R.C.P.(C), Associate Clinical Professor of Anesthesiology, UCLA School of Medicine; Staff Anesthesiologist, Centinela Hospital Medical Center, Los Angeles, California 90024; Frank A. Takacs, M.D. Assistant Professor, Department of Anesthesiology, UCLA School of Medicine, Los Angeles, California 90024

*Study from Wadsworth Veterans Administration Hospital, Los Angeles, Cal ifornia 90073.

Reprint requests: Frank A. Takacs, M.D., Department of Anesthesiology, UCLA School of Medicine, Los Angeles. California 90024.

†C. R. Bard. Inc., Murray Hill, New Jersey.

¥Sorensen Research Co., Sail Lake City, Utah 84115.

$\$$ Jelco Laboratories, Raritan, New Jersey 08869.

Canad. Anaesth. Soc. J., vol, 26, no. 2, March 1979
16 gauge) through basilic or cephalic veins to see how our success rate compared with other published results. To do this a tourniquet was applied to the upper arm and the antecubital fossa was cleaned with 70 per cent isopropyl alcohol. A wheal of one per cent lidocaine was introduced into the skin using a 25 gauge needle. The central venous pressure catheter was introduced into the basilic or cephalic vein by the method described by the manufacturer and it was advanced until the tip was judged to be in the right atrium. (Before insertion the catheter was laid on the patient's chest and arm overlying the route which it would take when inserted. The length of catheter yet uninserted when its tip was judged to be at the right atrium could then be estimated.) While the catheter was being inserted and advanced, the arm was abducted to 30 degrees from the side and the head was turned towards the site of insertion of the catheter. Either before or at the end of surgery a chest radiograph was used to determine the position of the catheter and its position was recorded.

In the second part of the study, we attempted to evaluate the effectiveness of a constantly running intravenous infusion while the catheter was being threaded up the arm towards the heart. It seemed reasonable that dilating the vein ahead of the moving catheter might give a higher success rate. For this part of the study we used the 15 gauge Sorensen catheter, since this technique is advocated by the manufacturer. The method of insertion was as previously described.

In the third part of the study, Bardic \#16 and Sorensen catheters were used and the catheter was introduced through the basilic vein. However, in this part of the study catheters were inserted until the tip was judged to be in the subclavian vein proximal to the junction of the cephalic and basilic veins and distal to the junction of the internal jugular with the innominate vein (Figure 1). In those catheters containing a wire stylet (Bardic), the stylet was withdrawn six inches and then the catheters were advanced slowly one-half inch at a time allowing two seconds between each one-half inch insertion. The purpose of the manoeuvre was to determine if the 


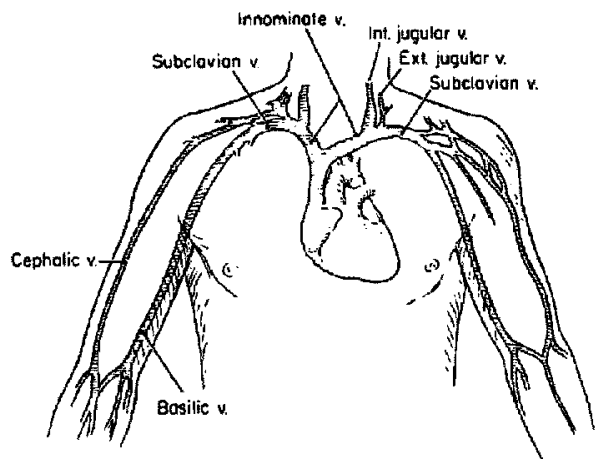

Figure I The anatomy of the central venous system.

slow insertion would allow the bloodstream to float the catheter into the correct position. The catheters were advanced until it was judged that the tip was in the right atrium. Immediately, or postoperatively, a chest radiograph was taken to confirm the position.

In the fourth part of the study the same technique was followed as in the third part, but the patients were positioned with the upper part of the body elevated from 45 to 90 degrees to the horizontal. The object was to determine if the sitting position would encourage gentle bending of the catheter and help it to follow the contours of the great veins into the heart. Bardic catheters (16 gauge) were used in this part of the study. This catheter was selected after 12-inch lengths of Bardic, Jelco, Deseret, and Sorensen catheters were held at an angle of 45 degrees to the horizontal. The angle to which the catheter bent under its own weight was measured to determine the tendency for the catheter to bend. With the stylet removed, the 16-gauge Bardic catheter was significantly softer than the other catheters and, therefore, we could expect the results with this catheter to be the best. As before, chest radiographs were taken to confirm the position of the catheter.

\section{Results And Discussion}

In the first part of the study, 76 central venous pressure catheters were inserted; 56 catheters were successfully placed and 20 catheters were judged unsuccessful for an overall success rate of 73.7 per cent, a success rate similar to that found by other workers. What is also of note is that the success rate using the basilic vein was 72.5 per cent, with 37 successful placements in 51 at- tempts. Most of the unsuccessful catheters were located in the internal jugular vein. The success rate using the cephalic vein was 76 per cent, with 19 successful placements in 25 attempts. Most of the unsuccessful catheter placements failed 10 negotiate the cephalic-subclavian venous junction. If they did negotiate this obstacle then almost all were correctly placed. In looking at the anatomy of the cephatic and basilic veins in Figure 1, one would expect that a significant number of catheters would be stopped at the cephalic-subclavian vein junction. This, in fact, is what we found. When the catheter passed this point the success rate was high. The reason for this becomes obvious when the anatomy of the arm veins is reviewed. Catheters inserted Ihrough the basilic vein would tend to pass along the cephalad wall of the great veins and so would have a greater tendency to go into incorrect positions (opposite subclavian or jugular veins, for example). If the catheter inserted through the cephalic vein can negotiate the cephalic-basilic junction, then the angle at which the catheter enters the basilic vein from the cephalic would predispose it to run along the caudad wall of the great veins and so increase the probability that it would be placed in a perfect monitoring position. Because many catheters failed to enter the subclavian vein from the cephalic, it would seem that improvement in the success rate would result from using the basilic vein only. Other workers have found that there is no difference in success rate between the two routes. ${ }^{2-3}$

The results of the second part of the study showed that a very low success rate of 43.7 per cent ( 7 successful placements in 16 attempts) was obtained using the intravenous infusion through the catheter. It would seem then that the catheter behaves rather like a hose pipe when water under pressure is turned on, tending to whip about inside the vein and, therefore, the poor success rate would be the result of this.

In carrying out the studies, it was our aim to try to eliminate the number of catheters which go up the internal jugular vein or into the opposite subclavian vein. When the third part of the study was carried out, it was hoped that slow insertion of the catheter would permit the blood stream to carry the tip of the catheter into the optimal position in the great veins of the chest. The results of this part of the study show that this was happening and that we were now obtaining a much more respectable 84 per cent success rate, with 46 successful placements in 55 attempls for the 16gauge Bardic catheters and an 80 per cent success 
rate, with 16 successful placements in 20 attempts with the 15-gauge Sorensen catheters. Since our success rate improved noticeably by slower advancement of the catheters, it would seem that allowing the blood stream to carry the catheter into the right atrium would be the method of choice and, therefore, the softer the catheter, theoretically, the more easily it would be carried by the blood stream and the better our results would be.

Part four of the study was therefore carried out using the softest catheter so that, with the patient sitting, the effect of gravity would tend to bend the catheter and allow it to travel more smoothly into the right atrium. This seemingly did happen since we have a 98 per cent success rate $(49$ successful placements in 50 attempts) for the passage of the catheter by this technique. It was important that the basilic vein was used as the site of insertion and that the stylet was not withdrawn until the tip of the catheter had passed the junction of the subclavian with the cephalic vein. If the stylet is withdrawn when the catheter tip is situated between the insertion of the cephalic vein into the subclavian and the insertion of the internal jugular vein into the subclavian, then it is very unlikely that the tip of the catheter will go either into the cephalic or the internal jugular veins. When the tip of the catheter has reached the internal jugular, the effect of gravity will tend to make the catheter run along the lower border of the innominate vein rather than up the internal jugular vein and it will proceed toward the right atrium.

We achieved our aim to find the best vein, the best catheter and the best technique. The method gave extremely good results and a far higher success rate than has been previously reported for unmonitored insertion of central venous pressure lines. II is possible, of course, that a similar success rate could be achieved with this technique using other brands of catheter.

It is hoped that these results will stimulate a resurgence of use of the veins of the arm for the introduction of central venous pressure catheters with the attendant low morbidity and minimal patient discomfort associated with a high success rate.

\section{SUMMARY}

Studies were carried out to develop a more successful method of inserting central venous catheters through arm veins without using electrocardiographic or fluoroscopic monitoring.
It was found that a running infusion attached to a Sorensen catheter gave a success rate of 48 per cent. The highest success rates ( 98 per cent) occurred when the basilic vein was used, with the patient positioned so that the upper part of the body was raised at 45-90 degrees to the horizontal and using a Bardic 16 gauge catheter with a special insertion technique, which is described. This represents a great improvement over the usual success rate of 70 to $80 \mathrm{per}$ cent.

\section{RÉSUMÉ}

Nos recherches ont tenté d'améliorer le coefficient de succès dans la mise en place de cathéters à pression veineuse centrale en utilisant les veines du bras comme point d'entrée sans avoir à recourir à l'électrocardiogramme ou à l'amplificateur de brillance. On a trouvé qu'un soluté intraveineux attaché à un cathéter de Sorensen mis en route au cours de la manceuvre d'introduction ne donnait un coefficient de succès que de 48 pour cent. Ce coefficient a èté à son meilleur ( 98 pour cent) lorsqu'on emploie la veine basilique comme point d'entrée, que l'on positionne le malade en position assise ou semiassise et qu'un cathéter de Bardic \# 16 est utilisé en prenant soin de retirer de six pouces le guide métallique poropre à ce cathéter lorsqu'on parvient à cette portion de la veine sous-clavière située entre les points d'arrivée de la céphalique et de la jugulaire interne. De cette façon, la souplesse du cathéter et l'effet de gravité dú à la position du malade entrainent presqu'à coup sûr le cathéter dans la direction du courant sanguin c'est-à-dire vers la veine cave supérieure. $\mathrm{Ce}$ taux de succès est nettement amélioré par rapport à ce qu'on publie généralement $(70$ à 80 pour cent).

\section{REFERENCES}

1. Webre, D.R. \& Arens, J.F. Use of cephalic and basilic veins for introduction of central venous catheters. Anesthesiology 38: 389-392 (1973),

2. Woods, D.G., Lumley, J., Russell, W.J., et al. The position of central venous catheters inserted through arm veins: a primary report. Anaesth. Intensive Care 2: 43-47 (1974).

3. LUMLEY, J. \& RusselL. W.J. Insertion of central venous catheters through arm veins. Antesth. Intensive Care 3: 101-104 (1975)

4. Deitel, M. \& Mclntrre. J.A. Radiographic confirmation of site of 52 central venous pressure calheters. Can. J. Surg. 121:600-605 (1971).

5. Gildar, D.L. The value of chest radiography in the localization of central venous pressure catheters. Can. Med. Assoc. J. 101: 363-364 (1969). 
6. Kellner, G.A. \& Smart, J.F. Percutaneous placement of catheters to monitor "central venous pressure". Anesthesiology 36: 515-516(1972).

7. LANGSTON, C.S. The aberrant central venous pressure catheter and its complications. Diagnostic radiology 100: 55-59 (1971).

8. SMith, B.F., Modell, J.H., TAub, M.L., et al. Complications of subclavian vein catheterization. Arch. Surg. 90: 228 (1965).

9. Thomas, T.V. Location of catheter tip and its impact on central venous pressure. Chest $61: 668-673$ (1972).

10. Kuramoto, T, \& Sakabe, T. Comparison of success in jugular versus basilic vein technics for cen.
Iral venous pressure catheter positioning. Anesth. Anal. 54: 696-607 (1975).

11. KhabiL, K.G., Parker, F.B., Mukherjee, N., el al. Thoracic duct injury. A comparison of jugular vein catheterization. JAMA 221:908-909 (1972).

12. English, I.C.W., FEw, R.M., Pigcott, J.F., el al. Percutaneous catheterization of the internal jugular vein. Anaesthesia 24:521-531 (1969).

13. Defalgue, R.J. Percutaneous catheterization of the internal jugular vein. Anesth. Analg. 53: 116-121 (1974).

14. Borua, A.R. Current status of intraclavicular subclavian catheterization. Ann. Thorac. Surg. 13: 615-624 (1972). 